Article

\title{
Does Informational Equivalence Preserve Strategic Behavior? Experimental Results on Trockel's Model of Selten's Chain Store Story
}

\author{
Papatya Duman $\mathbb{D}$ \\ Department of Economics, Paderborn University, 33098 Paderborn, Germany; papatya.duman@upb.de; \\ Tel.: +49-5251-60-3889
}

Received: 14 November 2019; Accepted: 26 December 2019; Published: 7 February 2020

\begin{abstract}
The purpose of this study is to experimentally test Trockel's game, which is a modelling of the classical Chain Store Game (CSG), and determine whether one of the two theories of Equality and Deterrence may better account for the observed behavior. The CSG is an example of a simple game in extensive form where the actual behavior of well-informed players cannot be expected to agree with the clear results of game theoretical reasoning. To explain the disagreement between the theory and the expected behavior, Trockel's game is proposed as an alternative modelling of the scenario. The existence of more than one equilibrium in Trockel's game opens a door for reputation building. This study is the first attempt to experimentally test this alternative game with the same purpose. According to my data, there is some evidence in favor of both Equality and Deterrence Hypotheses. However, since the strategies compatible with the Equality Hypothesis are played more frequently, I observe some patterns which share the same intuition with the Deterrence Hypothesis.
\end{abstract}

Keywords: Chain Store Game; reputation building; entry deterrence; Trockel's game

JEL Classification: C7; C9

\section{Introduction}

Rational behavior refers to a decision-making process that is based on making choices that result in an optimal level of benefit. Thus, in the framework of rationality, we make choices for the sake of our long-term benefit, even if we pay the price by sacrificing some short-term gains. However, if we are expected to be 'perfect rational' (rational at each single decision), the time-feature evaporates from the decision process-as the chain store's long-term payoff maximization is in conflict with this rationality concept in Selten's Chain Store Story.

The CSG is based on the one-stage Chain Store Game (see Figure 1), which is a two-player extensive form game between a monopoly (a chain store) and a (potential) entrant. In the CSG, the one-stage Chain Store Game is played consecutively for 20 rounds with the same monopoly and each of 20 different (potential) entrants, who are observing all plays before it is their own turn to play. According to Selten's story the potential entrant, who has enough capital, decides whether to enter the market or to stay out of the market completely. If this entrant decides to enter the market, then the monopoly employs one of two different monetary policies: Cooperative or Aggressive. A cooperative response yields considerably higher (duopoly) profits for both the monopoly and the entrant (both get 2 units of payoff, see Figure 1), as compared to an aggressive response (both get 0 unit of payoff, see Figure 1). In the latter case, however, the profit of the monopoly is much higher if the entrant does not enter the market (the monopoly gets 5 units of payoff, the entrant gets 1 unit of payoff, see Figure 1 ). The entrant prefers to stay out of the market and to use the capital in a different field instead, rather 
than to enter the market only to be met by an aggressive response. It is assumed that all the players wish to maximize their profits: for the monopoly, the total of the profits in 20-stage game and for an entrant, the profit of the one-stage game in which she decides. [1] discusses the CSG in two different ways: One is based on backward induction and the other on an intuitive deterrence argument. According to the Induction Hypothesis represented using the subgame perfect equilibrium concept, each entrant enters the market and then the monopoly always reacts with a cooperative monetary policy. According to the Deterrence Hypothesis, the monopoly should not behave in accordance with the Induction Hypothesis. By playing aggressively in the earlier stages, the monopoly may influence what future potential entrants think about its potential actions. If these beliefs turn into 'aggressive monopoly beliefs' early enough in the sequentially repeated game, the aggressive policy increases the monopoly's profits in the long run. If that is the case, it is optimal for all potential entrants to stay out from the beginning. This way, the monopoly would earn higher profits in the long run than it would earn by following the Induction Hypothesis. The disagreement between these two hypotheses is called the 'Chain Store Paradox' in [1] and in the following related literature.

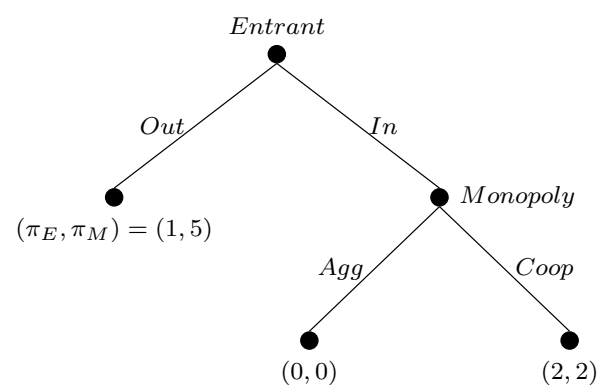

Figure 1. The One-Stage Chain Store Game.

Ref. [2,3] remove the assumption of complete information and present versions of the CSG with incomplete information. In Figure 2, you may find the two-player stage games of these CSG versions. The uncertainty regarding the monopoly player created by the incomplete information in both of the versions may trigger a fear in 'Aggressive' monetary policy, and may therefore deter the entrants from entering the market. As long as uncertainty exists, 'Aggressive' play against early entrants may be rational because it creates a reputation that would deter future potential entrants. These modifications of Selten's story were with largely the same approach via explicit introduction of incomplete information, but are obviously violating Selten's informational assumption. Therefore, they could hardly be seen as solutions to the paradox, although they nevertheless have been perceived as such in the literature.

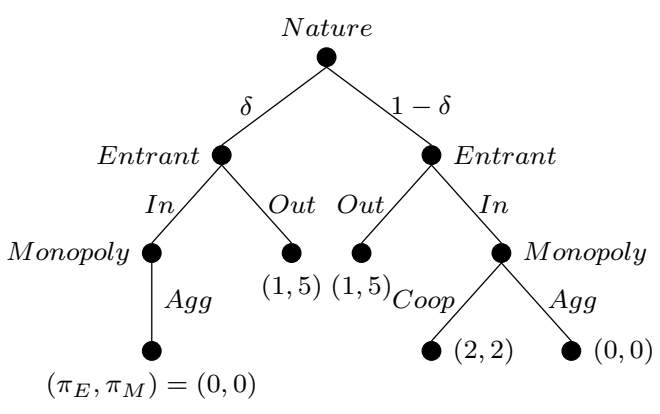

( a )

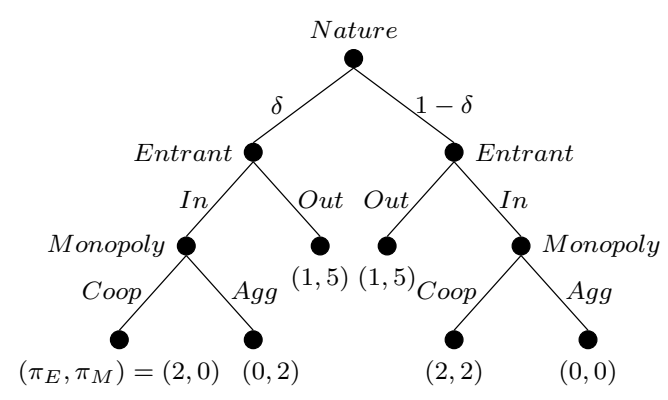

(b)

Figure 2. (a) Milgrom and Roberts (1982); (b) Kreps and Wilson (1982).

While the models of [2] and of [3] eliminate the complete information assumption, Trockel [4] keeps the complete information assumption but introduces an imperfect information game as an alternative model of Selten's Chain Store Story. [4] shows that the paradox vanishes when using the 
'right' richer model as the game theoretic presentation of Selten's story, and one does not need to eliminate the rational player assumption in order to explain the 'actual behavior' in a game with rational players. Nor does one need the framework of perfect information. In other words, he shows that the paradox is not in Selten's story, in Selten's game. In Trockel's game, Selten's story is preserved; the only difference is in the order of moves made by the players (see Figure 3). Trockel's game and Selten's game are normal-form equivalent and informationally equivalent as defined by $[5,6]^{1}$. Hence, the two-player stage games of [1,4] (Figure 1 and 3) are equivalent in terms of decision-making.

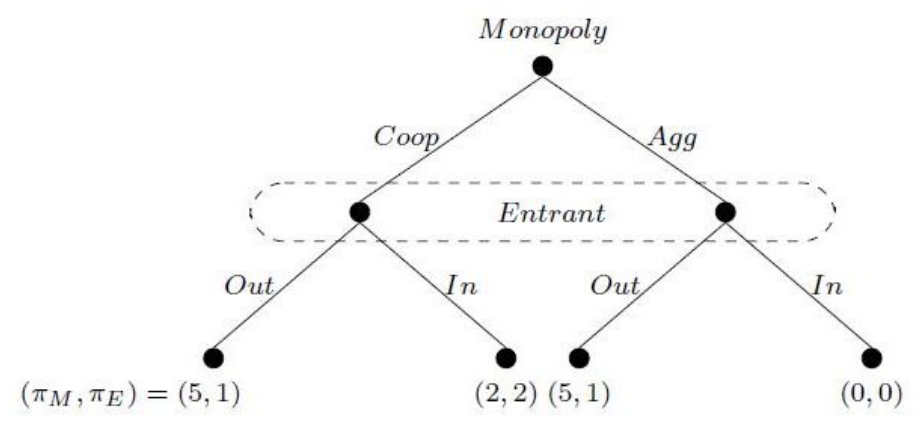

Figure 3. The One-Stage Trockel's Game.

The 'Cooperative-In' strategy set is the unique sequential (and perfect) equilibrium of Selten's game. However, in Trockel's game, together with 'Cooperative-In', the 'Aggressive-Out' strategy set is a sequential equilibrium and this equilibrium can be (re)enforced by building reputation. Reputation building is possible only if beliefs can be part of the model; thus, the existence of non-singleton information sets is the advantage of Trockel's game as compared with Selten's game. Furthermore, the existence of more than a single equilibrium allows for the chosen equilibrium strategy to be interpreted as a signal that reveals the kind of behavior that will consistently be displayed when the game is repeated. If that behavior can effectively be repeated in the next stages of the game, then reputation is built up via the entrants' Bayesian updating of their beliefs. The other advantage of the game is the imperfect information. The type of reputation that might be built in Trockel's game organizes the coordination of the choice in the respective equilibrium. Despite this additional structure Trockel's game is offering, [4] models exactly the same scenario as Selten's game-which is based on the Sure Thing Principle (see [7]), which guarantees the informational equivalence of Selten's and Trockel's games, is already embodied in von Neumann-Morgenstern utility functions assumed in standard Game Theory.

What Selten calls the Induction Hypothesis in the CSG is what I call Equality Hypothesis in Trockel's game: the players play in such a way that the earnings of each can be equal. This hypothesis implies that there is no strategic connection between the stages, i.e., the decisions at stage games are perceived as mutually independent. In Trockel's game, there is a situation in which every player can get the same amount of payoff-namely $2 * 20=40$-by following the path of the 'Cooperative-In' sequential equilibrium. The outcome of this equilibrium is the desirable by all the entrants, since there are no situations in which they are better off. However, for the monopoly player, there is another and better alternative: the path of the 'Aggressive-Out' sequential equilibrium in which she might use building a reputation expressed by the updated beliefs of the entrants during the course of the play. The monopoly player should motivate some of the entrants to play 'Out' by constantly playing 'Aggressive' starting from the very beginning of the game. A weaker version of the behavioral pattern in the path of the 'Aggressive-Out' sequential equilibrium is what I call Deterrence Hypothesis in Trockel's game. Like

1 One would apply transformations preserving the informational structure of a perfect information game: inflating the game and reverting the order of moves, both under preserving each player's information regarding other player's and one's own past moves. 
Selten explains, a monopoly player should decide on the basis of her intuition for how many of the last periods she wants to play 'Cooperative' (towards the end of the game, there is no concern about the reputation any more). She can have a higher payoff than 40 , if she can convince sufficiently many early entrants that she insists on the payoff 5-the payoff of the monopoly player when an entrant plays 'Out'.

Suppose that the monopoly player decided to play 'Cooperative' in the last 3 periods of the game. If the game is played in this way, she may get $17 * 5+2 * 3=91$. If some more than expected of the entrants believe in the Equality Hypothesis, the monopoly player can still get more than 40 . Imagine that not only the last 3 entrants, but also 10 of the other 17 entrants played 'In' and the other 7 played 'Out'. In this case, the monopoly player will get $7 * 5+10 * 0+2 * 3=41$, which is still better than 40 . This means that it is sufficient to deter 7 entrants from playing 'In'.

In the beginning of the game, if there are 2 to 3 entrants who decided 'In' when the monopoly player already decided to play 'Aggressive', this may lead the following entrants to fear losing and develop the tendency to the 'Out' decision. In the last phases of the game, even though the monopoly player is not planning to play 'Aggressive', this reputation effect can cause the 18th entrant's 'Out' decision, maybe even the 19th entrant's.

If the entrants believe that the monopoly player will follow the Deterrence Hypothesis, they also play accordingly. If the payoffs of the previously played entrants in all previous periods are 0 , the next entrant should play 'Out' unless she thinks that the game is sufficiently close to the end.

The purpose of this paper is to test Trockel's game and determine which of the two hypotheses better accounts for the outcome: the Equality Hypothesis or the Deterrence Hypothesis. Moreover, I aim to observe whether it is possible to deter the potential entrants in Trockel's game by building reputation. Understanding what affects the behavior of the players, how the behavior of the players changes, and whether the strategic behavior is preserved as a result of the equivalent information with the CSG are the main motivations of the study. Put differently, my goal is to study whether equivalence in information preserves strategic behavior. To the best of my knowledge, this study is the second experiment that clings to this scenario, and the first attempt in the literature that experimentally tests Trockel's game with the same purpose of understanding whether entry deterrence is possible. Selten's scenario had been tested in the laboratory for the first time and 20 entrants—as Selten suggests-are used for the first time. The introduction of investment (representing the capital in the story) in the design constitutes the major difference from the main design in [8].

My data cannot be explained solely by the Equality or the Deterrence Hypothesis, as either of these hypotheses is supported by some evidence. Although the strategies compatible with the Equality Hypothesis, 'Cooperative' and 'In' were played more frequently, I observe some similar patterns which share the same intuition with the Deterrence Hypothesis. More specifically, the history of the decisions, the round number (or, the number of the rounds left to play), previous earnings and the type of last decision by the opponent have an effect on the decisions of the entrants; and for the monopoly player, the type of the responses obtained after 'Aggressive' play matters as well as the round number (or, the number of the rounds left to play).

\section{Experimental Literature}

One of the referees for this article suggested in a footnote to hint to the political application of the analysis of the Chain Store problem to federal systems. In fact, when it comes to the importance of experimental results I think it is worth more than just a footnote. In particular, he wrote:

"In the U.S., for example, there are two main, state-sponsored parties. In many states, the Republicans ("Red State") or Democrats ("Blue State") are dominant. Sometimes a third party, of various sorts, may try to enter. But this entry usually takes place in one state, or at most a few states. The dominant party in that state is likely to spend more money on the campaigns (Governor, Senate, US House, etc.) to prevent the aspiring entrant from gaining a foothold. Or, do they? It's expensive, and doesn't really deter third parties, who don't expect to win anyway. Aaron King works some of this out in his book (pp. 35-40)." 
Also, in the law of economics literature, a similar problem has been an important issue under the name of predatory pricing. It is discussed in detail in Section 8 of Chapter 10: The Antitrust Laws in the famous book [9] by Richard Posner. The question whether predatory pricing could be punished by law when it could not be expected to be used by rational firms gave rise to the entrance of predatory pricing into the game theoretic literature. Without support from experimental evidence, the influence of game theoretical analysis on the clarification of this issue would remain quite limited.

Ref. [10] discusses the CSG from the perspective of Political Science. According to their study, politics is inherently strategic, and bluffing is the basic ingredient of this strategy. The CSG and its multiple versions are used by [10] to explain the role of reputation based on bluffing and commitment in international politics. Both bluffing and commitment are defined as tools to manipulate the expectation(s) of the opponent and, consequently, lead to a change in the opponent's behavior. They explain the modelling of [2,3] with bluffing, and the modelling of [4] with commitment (threat). They support the plausibility of benefit via reputation by real-life examples on developing and maintaining leadership.

The experiment literature includes several studies on the CSG, entry deterrence and predatory pricing: see e.g., [8,11-13], where [11] is one of the first attempts in the literature focusing experimentally on reputation and price predation. They use their borrower-lender game that has strategic aspects in common with the CSG, and their result shows strong reputation effects and the rationality of price predation.

The other referee wrote: "Trockel's game does not seem conceptually very different from a hawk-dove game. This similarity should be made explicit, and the experimental literature on hawk-dove should be mentioned." There are experimental studies focusing on reputation, deterrence, fairness or equity in the hawk-dove game: see for example [14,15].

However, the equivalent CSG modellings of Selten and of Trockel are neither informationally nor normal-form equivalent to the hawk-dove game. It is easy to write down a bi-matrix for the hawk-dove game, that, other than the Chain Store game, belongs to the class of so-called anti-coordination games and like the CSG has exactly the numbers 5, 2, 1 and 0 as occurring payoffs. It has two equilibrium payoff vectors $(1,5)$ and $(5,1)$ both Pareto optimal, while the CSG has two Pareto efficient equilibria with payoff vectors $(5,1)$ and $(2,2)$, where the first one's payoffs are independent of any (anti-) coordination. I therefore abstain from delving into the experimental literature of the hawk-dove game.

Ref. [12] test the asymmetric information version in [2] with 7 short-run players. In a session, 3 monopoly players and 4 entrants participate. One monopoly player faces 4 entrants, then the other 2 monopoly players face the entrants, and 4 entrants face the first monopoly player again by shuffling the order of the entrants. In 4-periods phases, usually 'Aggressive' play was preferred. Thus, they find support for the existence of a sequential deterrence equilibrium, even with a 'weak' monopoly player. Ref. [8] is the first in the literature to attempt to study the original CSG by employing experimental methods. Their study contains two treatments with 10 monopoly players and 15 entrants, respectively. Although the statistically significant support for the Deterrence Hypothesis amplifies as the number of the entrants increases, the support for entry deterrence with 'Aggressive' play is not observed. The authors concluded that 15 entrants were not adequate to make the deterrence argument effective and pointed out the necessity of a study with at least 20 entrants. Ref. $[8,16]$ offer suggestions for future studies of the CSG. Some of them call for an increase in the number of entrants (20 or more), another design of a laboratory experiment, and the use of Trockel's game. All these suggestions have been dealt with in the present study.

Ref. [13] presents a new version of the CSG with an additional move for the entrants in which they have the chance to either stay in the market or exit the market after the monopoly player's 'Aggressive' play. Unlike the other experimental studies, the participants may communicate with each other before submitting their decisions. They were informed about the following concepts: backward induction, the Nash equilibrium, and the Prisoner's Dilemma. Ref. [13] reports that none of the monopoly-type participants responded aggressively on a consistent basis. 
All experimental studies described above are conducted as paper-and-pencil experiments. Unlike these, a laboratory experiment is conducted in this study. The design is closer to the design of Experiment 3 in [8], but Trockel's game is used instead of Selten's game. The other difference from the design of [8] is in the use of the investment. Investment represents the necessary capital to establish a store for an entrant and the value of a store for a monopoly. Hence, a design without investment cannot properly motivate the participants as described in the scenario. Even if there is no data to examine the difference between the design with and the design without the investment, the results are expected to be different in each, based on the endowment effect (or loss aversion) in the literature [17].

The starting point of this study was the question of whether equivalence of information in two different games preserves strategic behavior. The conjecture was that the answer is negative by identifying the question with the framing effect [18]; i.e., the different results can be expected from the experiments simulating the CSG and Trockel's game. More specifically, ref. [4] changes the order of play in each stage game of the original game in an informationally equivalent way, and this change can be interpreted as a framing effect. Since I did not run any experiment based on Selten's original game and I cannot directly compare my results with the results of [8], this statement is not more than an anticipation that is not properly tested in this study.

Although Game Theory neglects the difference in the information flow in the CSG and Trockel's game, there are studies that negatively answer questions similar to those I asked to myself. Ref. [19] conducts three experiments with strategically equivalent games in extensive form, and the results show that there is a significant difference in how the games are played. Ref. [20] provides support for the importance of the order of play. According to their results, the advantage of a player in a game can be destroyed by changing the order of play. Hence, if it is assumed that the entrants have an advantage in the CSG, this can be damaged by Trockel's game.

\section{Experimental Design}

A laboratory experiment was designed to simulate Trockel's game. The design is almost the same as the last version of the design in [8]. The z-tree program by [21] was used to implement a laboratory experiment.

\subsection{Subjects}

In Spring 2017, the undergraduate students from several faculties of Istanbul Bilgi University (IBU) and Middle East Technical University (METU) were contacted and, 576 of them volunteered to participate. The students were recruited by the online system ORSEE [22].

The experiment was conducted in two laboratories: BELIS (Bilgi Economics Lab Istanbul) and BAEL (Behavioral and Experimental Lab, METU). In each university 12 sessions were conducted, for 24 sessions in total. Each session was completed in approximately 75 minutes.

For each session, 24 participants were invited. Written instructions were placed in every computer cubicle, so that the participants could follow them when they were aloud.

\subsection{Types}

In the beginning of the experiment, the 24 participants were assigned randomly to two roles: 4 of them were assigned to type $M$ (representing the monopoly player in the scenario) and 20 of them were assigned to type $\mathrm{E}$ (representing the entrants in the scenario). To distinguish between the players, a positive number was assigned to each player: numbers between 1-4 for type $M$ players; and numbers between 1-20 for type E players. Hence, the players in each session were numbered by M1, M2, M3, M4 and E1, E2,..., E20.

\subsection{In-Experiment Matchings}

There were 20 rounds in the experiment. Throughout the rounds, all the type $\mathrm{M}$ participants were active and matched with each type E participant, but in a different order. This implies that each 
type E participant played once with each type $\mathrm{M}$ participant, in total 4 times. Therefore, each type $\mathrm{E}$ participant was active in 4 out of 20 rounds and waited in the remaining 16 rounds for the next round in which she will be active or the termination of the experiment.

Due to the active and inactive rounds of type E participants, it was necessary to control the matchings of the two types of participants to observe their behavior in each phase of the rounds, to equalize their level of getting experienced in the experiment, and also to avoid the situations in which a type E participant would play successively. For those reasons, 20 rounds were divided into 4 sections, each containing 5 rounds. Each type E participant played once in a randomly chosen round of each section and in each section she matched with a different type $M$ participant. As soon as the experiment started, the program announced to all the type E participants the rounds in which they would be active, and with whom they would be matched in these rounds.

\subsection{Periods}

Each session included 20 rounds. Each round contained 4 independent one stages of Trockel's game (see Figure 4) and each session is made up of 4 twenty-round Trockel's games in which all type $\mathrm{M}$ participants played against all type E participants, but in a different order. In other words, every type $\mathrm{M}$ participant and her type E opponent (determined randomly in the beginning of the experiment) played one stage of Trockel's game in each round. Throughout the rounds, each type M participant played with a different type E participant and, consequently, a type M participant played once with each of the 20 type E participants.

The type M participants were not informed about the matches of the other type M participants, so the experiment was mutually independent for type M participants.

Each of the activated participants in every round was given 1 point. This is used to plug the investment instrument of the scenario into the experiment.

In each round, type $\mathrm{M}$ participants moved first by choosing one of the actions: 'Agg' or 'Coop'. Importantly, the decisions of type M participants were announced to none of type E participants. After the type $M$ participant made a decision, it was time for the type E participants activated in this round to make a decision. The type E participants chose one of the actions: 'In' or 'Out'.

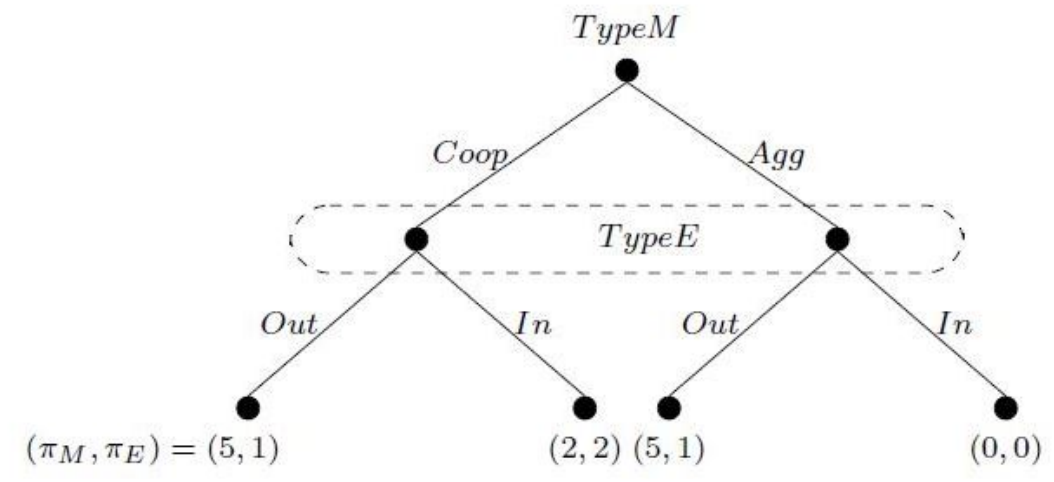

Figure 4. The One-Stage Game In a Round.

The payoffs were the same as used in the Trockel's game, as depicted in Figure 4. After the type E participants submitted their decisions, each of the active participants was informed about her own payoff as well as the payoff of the opponent. After the announcement of the payoffs, the experiment continued with the next round in which type $M$ participants were matched with four new type $E$ participants. After the completion of the 20th round, the experiment ended. 


\subsection{History Tables}

At the end of each round, the payoffs were stored in the history tables which were displayed on individual screens. By the help of these history tables, the participants could follow the related previous rounds at the rate allowed by their types.

The history table for type M participants portrayed information about their own decisions and payoffs for all previous rounds as well as the decisions of their opponents in all the previous rounds. In Table 1, you may see an example of the history table for a type M participant while the round 3 is ongoing.

Table 1. An Example of a History Table of a Monopoly Player.

\begin{tabular}{cccc}
\hline Round & My Decision & My Opponent's Decision & My Points \\
\hline 1 & Coop & Out & 5 \\
2 & Agg & In & 0 \\
3 & $?$ & $?$ & $?$
\end{tabular}

The data in the table above comes from the software calculation results.

The history table for active type E participants provided information about the payoffs (not decisions) of the opposing type $\mathrm{M}$ participant as well as the decisions and payoffs of the previously active type E participants, who already had played against this type M participant in previous rounds. In Table 2, you may find an example of the history table for a type $\mathrm{E}$ participant while the round 3 is ongoing.

Table 2. An Example of a History Table of an Entrant.

\begin{tabular}{cccc}
\hline Round & $\begin{array}{c}\text { The Decision of Type E } \\
\text { Who was Active in that Round }\end{array}$ & $\begin{array}{c}\text { The Points of Type E } \\
\text { Who was Active in that Round }\end{array}$ & $\begin{array}{c}\text { The Points of } \\
\text { the Opponent }\end{array}$ \\
\hline 1 & Out & 1 & 5 \\
2 & In & 0 & 0 \\
3 & $?$ & $?$ & $?$ \\
\hline
\end{tabular}

The data in the table above comes from the software calculation results.

A waiting type E participant's table contains the information about the matches of the type $\mathrm{M}$ participant with whom this type E participant was scheduled to match next; i.e., the table is the same as that of the active type E participant who was matched with that type M participant.

\subsection{Treatments}

There were two treatments:

- $\quad$ First treatment T1: Trockel's game is used with the original payoffs.

- Second treatment T2: It differs from T1 in the payoff of the monopoly when the outcome is 'Aggressive-Out'. In T2, the payoff increased from 5 to 10 when the entrant chose 'Out', to enhance the appeal of 'Aggressive' play.

\subsection{Questionnaire and the Payment}

A questionnaire that helps to understand the reasons for the participants' behavior during the experiment was started after the completion of the rounds. This questionnaire was the version of the one in [16]. The questions were adapted to the modification of Trockel's game, but their aims were preserved (see Appendix A).

After the questionnaire, the participants were paid their earnings and the session was completed. The total amount of what a type M participant earned in each round was paid in Turkish Lira (TL) and the total amount of what a type E participant earned in each round in which she was activated was first multiplied by 5 and then paid in TL. 


\section{Results}

From each of the two universities, 288 undergraduate students took part in the sessions. Hence, 480 entrant data points and 96 monopoly player data points were collected, which are given in Table 3 .

The mean payment of monopoly players was 46.86 TL (IBU 43.71, METU 49.96) in T1 and 71.5 TL (IBU 69.59, METU 73.42) in T2. The mean payment of entrants was 28.17 TL (IBU 28.71, METU 27.62) in T1 and 27.06 TL (IBU 26.63, METU 27.5) in T2. The lowest payoff earned by the METU monopoly players is $41 \mathrm{TL}$, exceeding the $40 \mathrm{TL}$ that might have been earned by adhering to 'Cooperative-In'. Except for two of the IBU monopoly players (although each played 'Aggressive' at least 12 times), all participants gained more than $40 \mathrm{TL}$. The mean entrant payoff is approximately $12 \mathrm{TL}$, which is also less than the amount possible by the 'Cooperative-In' sequential equilibrium.

Table 3. Pooled Data.

\begin{tabular}{ccccc}
\hline Round & Agg. Frequency & P(Agg) & In Frequency & P(In) \\
\hline 1 & 17 & $18 \%$ & 65 & $68 \%$ \\
2 & 35 & $36 \%$ & 62 & $65 \%$ \\
3 & 22 & $23 \%$ & 64 & $67 \%$ \\
4 & 33 & $34 \%$ & 66 & $69 \%$ \\
5 & 32 & $33 \%$ & 68 & $71 \%$ \\
6 & 32 & $33 \%$ & 72 & $75 \%$ \\
7 & 34 & $35 \%$ & 69 & $72 \%$ \\
8 & 25 & $26 \%$ & 78 & $81 \%$ \\
9 & 27 & $28 \%$ & 74 & $77 \%$ \\
10 & 21 & $22 \%$ & 84 & $88 \%$ \\
11 & 32 & $33 \%$ & 77 & $80 \%$ \\
12 & 31 & $32 \%$ & 70 & $73 \%$ \\
13 & 32 & $33 \%$ & 81 & $84 \%$ \\
14 & 34 & $35 \%$ & 74 & $77 \%$ \\
15 & 25 & $26 \%$ & 82 & $85 \%$ \\
16 & 28 & $29 \%$ & 70 & $73 \%$ \\
17 & 26 & $27 \%$ & 79 & $82 \%$ \\
18 & 22 & $23 \%$ & 73 & $76 \%$ \\
19 & 20 & $21 \%$ & 77 & $80 \%$ \\
20 & 16 & $17 \%$ & 82 & $85 \%$ \\
\hline Total & 544 & & 1467 & \\
Mean & 27.20 & 0.29 & 73.35 & 0.76 \\
Std. Dev. & 5.98 & 0.07 & 6.55 & 0.07 \\
\hline
\end{tabular}

In Table 3, the Agg. Frequency column shows the aggressive frequencies by round number. The monopoly players played 'Aggressive' on $29 \%$ of $96^{*} 20$ rounds. One cannot say that the trend of the aggressive frequencies is upward or downward, but it is certain that the frequencies in the last 5 rounds decrease by the round number (see Figure 5).

In Table 3, the In Frequency column shows the entry frequencies by entrance order/round number. Altogether, the entrants played 'In' on 76\% of $96^{* 2} 20$ rounds. One can easily see that In Frequency varies as the round number increases (see Figure 6). Moreover, with a few deviations, it increases monotonically. 


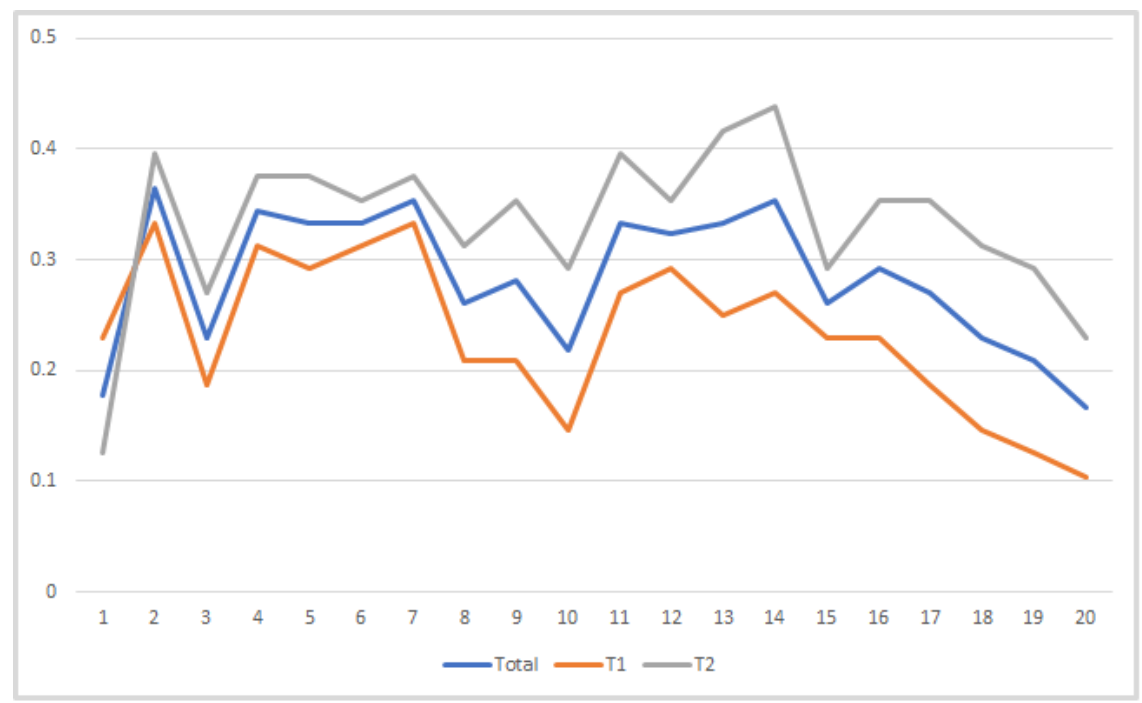

Figure 5. The Proportion of Aggressive Play over Rounds.

8 monopoly players $(8 \%)$ always played 'Cooperative', while none of the monopoly players always played 'Aggressive' and only 3 monopoly players (4\%) played 'Aggressive' at least 17 times . The ones who played a 50-50 mix of 'Cooperative' and 'Aggressive' are 5 out of 96 monopoly players (5\%) and those who played 'Aggressive' at least 10 times are 17 out of 96 monopoly players $(18 \%)$. Hence, approximately $86 \%$ of the monopoly players played a different mixed strategy than 50-50. A one-sided t-test rejects the hypothesis that subjects mix 'Cooperative' and 'Aggressive' with equal probabilities: 'Cooperative' is played significantly more frequently than 'Aggressive' ( $p$-value $3.3067 \times 10^{-15}$ ). Moreover, I also focused on the post-behavior of the monopoly players who reached a 40 payoff within the first 17 rounds. After gaining a 40 payoff, the monopoly players played 'Aggressive' less frequently than how they played before the 40 payoff ( $p$-value 0.037 ).

The number of the entrants who always played 'In' is 194 out of 480 entrants (40\%), while only 12 entrants (2.5\%) always played 'Out', and 77 entrants (16\%) played a 50-50 mix of 'In' and 'Out'. Among these 77 entrants, 46 entrants (9.5\%) chose 'Out' as the first two decisions. Hence, approximately $41.5 \%$ of the entrants played a different mixed strategy than 50-50. A one-sided t-test rejects the hypothesis that subjects mix 'In' and 'Out' with equal probabilities: 'In' is played significantly more frequently than 'Out' ( $p$-value $\left.9.17107 \times 10^{-80}\right)$.

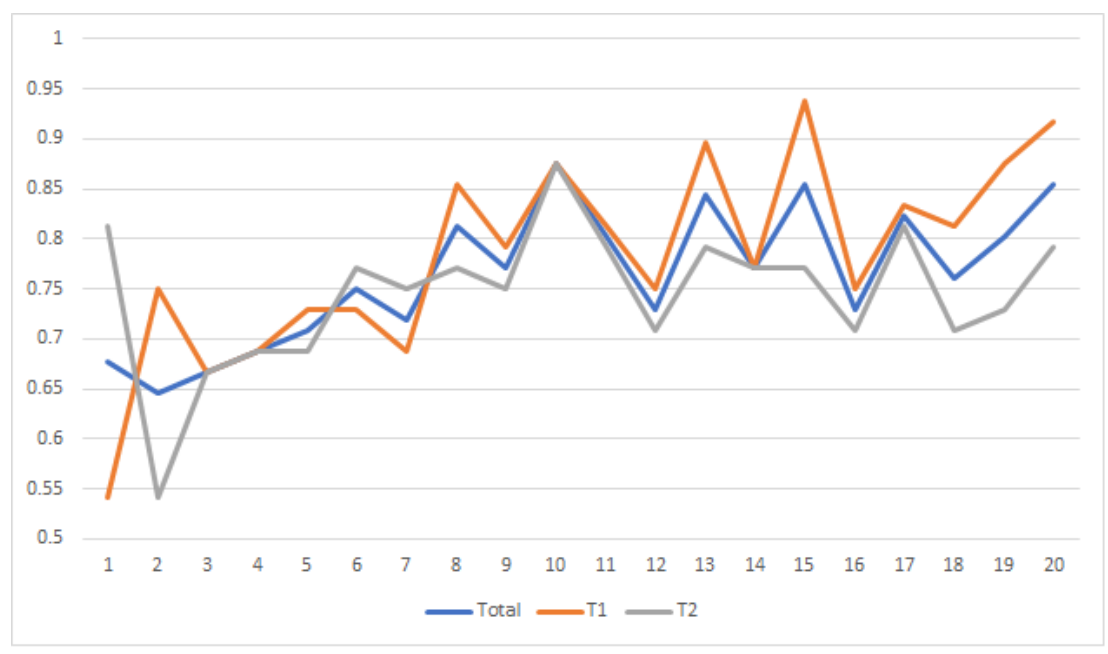

Figure 6. The Proportion of In Play over Rounds. 
To see some patterns that the data might have, we turn to the analysis of the Deterrence Hypothesis. The essence of the Deterrence Hypothesis states that the behavior of the entrants is not invariant to their order of play. To confirm whether this conjecture is valid for the data, all the decisions of each round were listed in such a way that the 'Aggressive' ('Cooperative') decision is coded as 1 (0), so that 20 different lists were such constructed. The Kruskal-Wallis H (one-way) test was conducted on these lists to determine whether there are any statistically significant differences between their means. The results show that the behavior of the monopoly players is not invariant across rounds ( $p$-value 0.0147), nor is the behavior of the entrants ( $p$-value 0.0004 ). Thus, the behavior of the monopoly players is not the same in all rounds, nor is the behavior of the entrants the same across all 4 rounds of play. It is important to understand whether the variability in the decisions of both monopoly players and entrants is due to the round number, or to the change in the information related to the round number might be the basis of the variability. Later, in Section 3.1, I employ logistic regression analyses to answer this question.

The proportion of 'Aggressive' play from round 1 to round 15 by the monopoly players significantly exceeds the same proportion in rounds 16 to 20 (one-sided t-test, $p$-value 0.0022) (see Figure 5). Please note that this difference may also be attributed to end effect [23]. Figure 5 leads us to consider the difference between the proportion of 'Aggressive' play by the monopoly players from round 1 to round 5 and the corresponding proportion in the last 5 rounds. The mentioned proportion in the first 5 rounds is greater than the one in last 5 rounds, and this difference is significant (one-sided $t$-test, $p$-value 0.004). Additionally, there is a significant difference between the proportion of 'Aggressive' play from rounds 6 to 15 and the corresponding proportion in the last 5 rounds (one-sided $t$-test, $p$-value 0.00093): The proportion between rounds 6 and 15 is greater. Finally, the difference between the proportion of 'Aggressive' play from rounds 1 to 5 and the corresponding proportion between rounds 6 to 15 is not a significant difference. Hence, the mean frequency of 'Aggressive' play in the first 15 rounds statistically exceeds the mean frequency of 'Aggressive' play in the last 5 rounds.

It is also important to determine whether the behavior of the entrants varies over sections. For this purpose, for each section I listed the numbers of 'In' responses to each monopoly player during the section. The Kruskal-Wallis H (one-way) test was conducted on these four lists to determine whether there are statistically significant differences between their means. The null hypothesis of equal means across all 4 sections is soundly rejected ( $p$-value $\left.4.08 \times 10^{-05}\right)$. Hence, the choices of the entrants are not the same across the four sections.

The present experiment includes two treatments that differ from each other in their payoff (either 5 or 10) to the monopoly player when the outcome is 'Aggressive-Out'. An increase in the proportion of 'Aggressive' choices is expected with the increase in payoff from 5 to 10, and the proportion of 'In' play is expected to decrease. A Kruskal-Wallis $\mathrm{H}$ (one-way) test was conducted on the number of 'Aggressive' play and separately on the number of 'In' play to test these two hypotheses about the effect of change in payoff. The results of the test show that monopoly players do not play the same way in the two treatments ( $p$-value 0.0001 ). As expected, they support an increase in the proportion of 'Aggressive' play for the monopoly player. However, the expected statistically significant decrease in the 'In' play of the entrants is not supported ( $p$-value 0.28). As a result, in 'Aggressive-Out' games, the choice of the entrants is not affected by the payoff of the monopoly player, while the choice of the monopolies is affected.

\subsection{Logistic Regression Analysis}

In this section, I present the results of logistics regression analyses conducted on the probability of an 'In' decision of the entrants or of an 'Aggressive' decision of the monopoly players. In the analyses, I use the fixed-effects and the random-effects model, which differ in the approach on the effects of the time-invariant variables. In fixed-effects model, the effects of the time-invariant variables are assumed to be time-invariant (so they are omitted), while it does not hold for the random-effects model. For example, one can suppose that the effect of the university in which a student studies does not 
vary through the rounds (fixed effect), but on the other hand, since a woman is expected to be more risk-averse than a man, she may change her behavior within the stages of an experiment under the pressure of losing(random effect).

Below, first you may find the results of two different logistics regression analyses of the entrants with each of two models, and later, the results of two different logistics regression analyses of the monopoly players with each of two models. In each table below, the first row of an independent variable presents the results of the fixed-effects model; and its second row belongs to the analysis with the random-effects model.

The panel data is obtained by combining the observations collected from IBU and METU participants, and then panel logistic regression analyses were conducted to estimate the probability of an entrant choosing ' $I n$ '. The binary dependent variable is 1 if the decision is ' $\mathrm{In}^{\prime}$, and 0 if it is 'Out'. The independent variables are as followings: Agg is the number of 'Aggressive' decisions of the current monopoly player in the previous rounds, Uncertain is the number of Uncertain decisions of the current monopoly player in the previous rounds ${ }^{2}$, Round represents the number of the playing round, PRP is the payoff gained from the last play, LRA is a binary variable indicating if the last decision of the current monopoly player is 'Aggressive' or not, LRU is a binary variable indicating if the last decision of the current monopoly player is 'Uncertain' or not, Order represents the total number of consecutive decisions of the entrants (i.e., 1st or 2nd decision), Uni indicates at which university the entrant studies (at METU or not), Faculty represents in which faculty the entrant studies (Arts and Sciences/Social Sciences, Engineering, Architecture, Economics and Administrative Sciences/Business, Communication, Law or Education), Gender represents whether the entrant is female or not, Game Theory indicates if the entrant took a course on Game Theory or not, and ID is the identity number of the student.

Table 4 presents the result of logistic regression analysis with the fixed-effect model on the panel data gathered from the entrants. The model is meaningful $(p$-value $<0.01)$ and all variables contribute significantly to the probability of an 'In' decision. While Round and PRP have positive effects on the probability, the other variables have a negative effect.

The odd ratio of the variable Agg is approximately 0.79 as shown in Table 4. If Agg increases by 1 unit, then the odd ratio of an 'In' decision decreases by a factor of $21 \%$. That means that an increase in Agg observations results in a decrease in the probability of an 'In' decision. Hence, it is evident that the entrants are affected by the decisions of the monopoly players and, accordingly, they decide to either enter or stay out of the market. Furthermore, the entrants are affected by the undetermined decisions of the monopoly players in the same manner as they are affected by the 'Aggressive' decisions since the odd ratio of the variable Uncertain is approximately 0.81 . If Uncertain increases by 1 unit, then the odd ratio of an 'In' decision decreases approximately by a factor of $19 \%$. In other words, an increase in Uncertain observations decreases the probability of an 'In' decision. The entrants are reinforced to enter the market when they observe more 'Cooperative' decisions; alternatively, they decide not to enter the market (i.e., are deterred from entering the market) when they observe more 'Aggressive' play.

The variable Round is one of the positive-effect variables with the odd ratio approximately 1.16. Whenever Round increases by 1 unit, the odd ratio of the 'In' decision increases approximately by a factor of $16 \%$. The probability of an 'In' decision increases if Round increases. One can infer that this result is evidence that entrants were sensitive to the round number or the information changing as a result of the increase in the round number.

The other positive-effect-predictor is PRP: the odd ratio is approximately 1.22 . The probability of an 'In' decision is higher if PRP is high. This variable and its effect can be interpreted as a risk attitude, since entering the market is simultaneously the decision of risking the investment. If there is

2 If the payoff of a monopoly player is 1, the entrant of that round plays 'Out'. Hence, this payoff does not contain any information related to the decision of the monopoly player. 
something in the 'pocket', one may assume risk more often; i.e., an entrant may have an incentive to choose 'In' again if she has already earned 1 more point with 'In'.

Table 4. Entrants-Panel Logistic Regression 1.

\begin{tabular}{ccccccc}
\hline Action & Odd Ratio & Std.Err. & $\boldsymbol{z}$ & $\boldsymbol{P}>|\boldsymbol{z}|$ & \multicolumn{2}{c}{ \%95 Conf. Interval } \\
\hline Agg & 0.7868992 & 0.0330637 & -5.70 & $0.000^{* * *}$ & 0.7246922 & 0.8544459 \\
& 0.7723197 & 0.0306647 & -6.51 & $0.000^{* * *}$ & 0.714497 & 0.8348219 \\
Uncertain & 0.813862 & 0.0371601 & -4.51 & $0.000^{* * *}$ & 0.7441934 & 0.8900528 \\
& 0.8244335 & 0.0355853 & -4.47 & $0.000^{* * *}$ & 0.7575564 & 0.8972145 \\
Round & 1.157306 & 0.0247897 & 6.82 & $0.000^{* * *}$ & 1.109725 & 1.206927 \\
& 1.142695 & 0.022985 & 6.63 & $0.000^{* * *}$ & 1.098522 & 1.188645 \\
PRP & 1.223414 & 0.1132568 & 2.18 & $0.029^{*}$ & 1.020409 & 1.466807 \\
Uni & 1.423831 & 0.1165063 & 4.32 & $0.000^{* * *}$ & 1.212853 & 1.67151 \\
& 1 & $($ omitted) & & & & \\
Faculty & 0.7344255 & 0.1119438 & -2.03 & $0.043^{*}$ & 0.5447591 & 0.9901271 \\
Gender & 1 & $($ omitted) & & & & \\
Game Theory & 0.9905217 & 0.0520703 & -0.18 & 0.856 & 0.8935472 & 1.098021 \\
Constant & 1 & $($ omitted) & & & & \\
& 1.6538374 & 0.0976447 & -2.85 & $0.004^{* * *}$ & 0.4879222 & 0.8761711 \\
& 1 & $($ omitted) & & & & \\
& 2.594987 & 0.213229 & 2.12 & $0.034^{*}$ & 1.024229 & 1.872814 \\
\hline
\end{tabular}

Std.Err. $=$ Standard Error; Conf. $=$ Confidence; $*$ P $<0.05 ; * * *: \mathrm{P}<0.01$.

Another logistics regression analysis was conducted with the random-effects model by using the same predictor variables. In Table 4, you may also find the results of it. All the predictor variables of the fixed-effects model to estimate the probability of 'Aggressive' decision are also predictor variables of the random-effects model. Among the time-invariant variables, Uni, Gender have a negative effect on the probability, while Game Theory has positive effect.

In Table 4 , the odd ratio of the variable Uni is approximately 0.73 , i.e., the probability of an METU entrant to have an 'In' decision is less than the probability of an IBU entrant. As stated in Table 4, the odd ratio of the variable Gender is approximately 0.65 . This implies that a female entrant's probability of an 'In' decision is smaller than a male entrant. This observation can be explained by the difference in the risk attitudes between the genders.

Some of the participants were the students who already took some courses on Game Theory. According to the odd ratio greater than 1, the probability of an 'In' decision is higher if an entrant had already learnt some basic concepts of Game Theory.

In Table 5, the result of the second logistic regression analysis on the entrants' panel data with fixed-effects model is presented. The model is meaningful ( $p$-value $<0.01)$. The variables PRP, LRA and LRU contribute significantly to the probability of an 'In' decision. While PRP has positive effects on the probability, LRA and LRU have a negative effect.

The odd ratio of the variable PRP is approximately 1.37 as shown in Table 5 . This means that the probability of an 'In' decision is higher if PRP is high. In other words, an entrant may have an incentive to choose 'In' again if she has already earned 1 more point with 'In'.

The odd ratio of the variable LRA is approximately 0.40 , i.e., if LRA takes a 0 value, the probability of an 'In' decision is higher in comparison to the situation where LRA is 1 . The same is also valid for LRU. In other words, the probability of an 'In' decision decreases when the entrants observe that the last round action is not 'Cooperative'.

In Table 5, you may also find the results of the same logistics regression analysis with random-effects model. The time-invariant variables Gender and Game Theory are significant predictors along with PRP, LRA and LRU as in the analysis with the fixed-effects model. 
Table 5. Entrants-Panel Logistic Regression 2.

\begin{tabular}{|c|c|c|c|c|c|c|}
\hline Action & Odd Ratio & Std.Err. & $z$ & $P>|z|$ & \multicolumn{2}{|c|}{$\% 95$ Conf. Interval } \\
\hline \multirow[t]{2}{*}{ PRP } & 1.368848 & 0.1043251 & 4.12 & $0.000^{* * *}$ & 1.178914 & 1.589383 \\
\hline & 1.517539 & 0.1053483 & 6.01 & $0.000^{* * *}$ & 1.324491 & 1.738724 \\
\hline \multirow[t]{2}{*}{ LRA } & 0.4019908 & 0.0698842 & -5.24 & $0.000 * * *$ & 0.2859162 & 0.5651888 \\
\hline & 0.4431788 & 0.0690054 & -5.23 & $0.000 * * *$ & 0.3266194 & 0.6013341 \\
\hline \multirow[t]{2}{*}{ LRU } & 0.5323112 & 0.0885989 & -3.79 & $0.000^{* * *}$ & 0.3841404 & 0.7376346 \\
\hline & 0.4844501 & 0.0727617 & -4.83 & $0.000^{* * *}$ & 0.3609136 & 0.6502717 \\
\hline \multirow[t]{2}{*}{ Uni } & 1 & (omitted) & & & & \\
\hline & 0.7629754 & 0.1124712 & -1.84 & 0.066 & 0.5715231 & 1.018561 \\
\hline Faculty & 1 & (omitted) & & & & \\
\hline \multirow[t]{2}{*}{ Gender } & $\begin{array}{c}0.9960464 \\
1\end{array}$ & $\begin{array}{l}0.0511204 \\
\text { (omitted) }\end{array}$ & -0.08 & 0.938 & 0.9007268 & 1.101453 \\
\hline & 0.6699686 & 0.097497 & -2.75 & $0.006^{* * *}$ & 0.5037135 & 0.8910977 \\
\hline \multirow[t]{2}{*}{ Game Theory } & 1 & (omitted) & & & & \\
\hline & 1.361758 & 0.2046238 & 2.05 & $0.04 *$ & 1.014365 & 1.828122 \\
\hline Constant & 4.732442 & 1.144424 & 6.43 & 0.000 & 2.946071 & 7.601992 \\
\hline
\end{tabular}

Std.Err. = Standard Error; Conf. $=$ Confidence; ${ }^{*}: \mathrm{P}<0.05 ;{ }^{* * *}: \mathrm{P}<0.01$.

As in the results of the previous random-effects model, a female entrant's probability of an 'In' decision is smaller than a male entrant's (the odd ratio is 0.67 ); and the probability of an 'In' decision is higher if an entrant had already learnt some basic concepts of Game Theory (the odd ratio is 1.36).

Four panel logistic regression analyses with the fixed-effects and random-effects model were conducted to estimate the probability of a monopoly player choosing 'Aggressive' on the panel data gathered from the monopoly players. The binary dependent variable is 1 if the decision is 'Aggressive', and 0 if it is 'Cooperative'. The independent variables are the following: Agg-In is the number of Agg-In outcomes observed in the previous rounds, Coop-In is the number of Coop-In outcomes observed in the previous rounds, Agg-Out is the number of Agg-Out outcomes observed in the previous rounds, Round represents the number of the playing round, LRI is a binary variable indicating whether the decision of the previously played entrant in the previous round against the monopoly player about to be faced is 'In' or not, Uni indicates at which university the entrants studies (at METU or not), Faculty represents in which faculty the entrant studies (Arts and Sciences/Social Sciences, Engineering, Architecture, Economics and Administrative Sciences/Business, Communication, Law or Education), Gender represents whether the entrant is female or not, Game Theory indicates if the entrant took a course on Game Theory or not, and ID is the identity number of the student.

Table 6 summarizes the results of the panel logistic regression analysis of the monopoly player with the fixed-effects model. The model is meaningful ( $p$-value $<0.01$ ). Agg-In and Agg-Out are statistically significant predictors of the probability of an 'Aggressive' decision. While Agg-Out has a positive effect on the probability, Agg-In has a negative effect on the probability.

The odd ratio of the variable Agg-In approximately 0.79. If Agg-In increases by 1 unit, the odd ratio of the 'Aggressive' decision decreases approximately by a factor of $21 \%$, i.e., an increase in the number of Agg-In observations causes a lower probability of an 'Aggressive' decision. Table 6 also shows that the odd ratio of the variable Agg-Out as approximately 1.50. If the number of Agg-Out increases by 1 unit, the odd ratio of the 'Aggressive' decision increases approximately by a factor of $50 \%$. Thus, the probability of an 'Aggressive' decision increases if the number of Agg-Out observations increases.

I replicated the logistic regression analysis by using the random-effects model. Table 6 also presents the results of this analysis: none of the time-invariant variables has a predictive power on the independent variable. As mentioned above, in the analysis with the fixed-effects model, Agg-In and Agg-Out are the significant predictor variables. However, this is not valid for the analysis with the random-effects model: instead of Agg-In, Coop-In is a significant predictor variable along with Agg-Out. Like Agg-In, Coop-In has negative effect on the probability of an 'Aggressive' play. If Coop-In increases by 1 unit, the odd 
ratio of the 'Aggressive' decision decreases approximately by a factor of $12 \%$. This is the only difference between two models I observed in all analyses done in this study.

Table 6. Monopoly-Panel Logistic Regression 1.

\begin{tabular}{|c|c|c|c|c|c|c|}
\hline Action & Odd Ratio & Std.Err. & $z$ & $P>|z|$ & \multicolumn{2}{|c|}{$\% 95$ Conf. Interval } \\
\hline \multirow[t]{2}{*}{ Agg-In } & 0.7811345 & 0.042526 & -4.54 & $0.000 * * *$ & 0.7020778 & 0.8690933 \\
\hline & 1.00305 & 0.0528328 & 0.06 & 0.954 & 0.9046656 & 1.112134 \\
\hline \multirow[t]{2}{*}{ Agg-Out } & 1.495115 & 0.1235306 & 4.87 & $0.000 * * *$ & 1.271586 & 1.757937 \\
\hline & 1.608184 & 0.112841 & 6.77 & $0.000 * * *$ & 1.401554 & 1.845278 \\
\hline \multirow[t]{2}{*}{ Coop-In } & 1.007013 & 0.0260432 & 0.27 & 0.787 & 0.9572416 & 1.059373 \\
\hline & 0.8806632 & 0.0221948 & -5.04 & $0.000^{* * *}$ & 0.8382191 & 0.9252565 \\
\hline \multirow[t]{2}{*}{ Uni } & 1 & (omitted) & & & & \\
\hline & 0.8516906 & 0.1717452 & -0.80 & 0.426 & 0.5736344 & 1.264528 \\
\hline \multirow[t]{2}{*}{ Faculty } & 1 & (omi & & & & \\
\hline & 0.9682641 & 0.0615046 & -0.51 & 0.612 & 0.8549193 & 1.096636 \\
\hline \multirow[t]{2}{*}{ Gender } & 1 & (om & & & & \\
\hline & 0.9346882 & 0.1849402 & -0.34 & 0.733 & 0.6342281 & 1.377489 \\
\hline \multirow[t]{2}{*}{ Game Theory } & 1 & (omitted) & & & & \\
\hline & 1.320798 & 0.2717673 & 1.35 & 0.176 & 0.8824567 & 1.976877 \\
\hline Constant & 0.4324311 & 0.1158132 & -3.13 & 0.002 & 0.2558286 & 0.730945 \\
\hline
\end{tabular}

Std.Err. $=$ Standard Error; Conf. $=$ Confidence; ${ }^{* * *}: \mathrm{P}<0.01$.

In Table 7, you may find the results of the second logistic regression analysis on the monopoly players' panel data with fixed-effects model. The model is meaningful ( $p$-value $<0.01)$ and LRI is not a significant predictor of the dependent variable.

It is an important observation that LRI has no predictive power on the probability of 'Aggressive' play. One can interpret this result as follows: The monopoly players did not take the one-round reactions of the entrants as one of the main driving forces of their decisions; i.e., they were not myopic.

The second logistics regression of the monopoly players is also replicated by the random-effects model. In Table 7, the result of this analysis is presented. LRI as well as none of the time-invariant variables have a significant effect on the probability of an 'Aggressive' decision.

Table 7. Monopoly-Panel Logistic Regression 2.

\begin{tabular}{|c|c|c|c|c|c|c|}
\hline Action & Odd Ratio & Std.Err. & $z$ & $P>|z|$ & \multicolumn{2}{|c|}{$\% 95$ Conf. Interval } \\
\hline \multirow[t]{2}{*}{ LRI } & 1.068754 & 0.1542534 & 0.46 & 0.645 & 0.8054228 & 1.418182 \\
\hline & 0.9924131 & 0.1425513 & -0.05 & 0.958 & 0.748902 & 1.315104 \\
\hline \multirow[t]{2}{*}{ Uni } & 1 & (omitted) & & & & \\
\hline & 1.084298 & 0.3698836 & 0.24 & 0.812 & 0.5556231 & 2.116005 \\
\hline \multirow[t]{2}{*}{ Faculty } & 1 & (omit & & & & \\
\hline & 0.9248028 & 0.1001964 & -0.72 & 0.471 & 0.7478715 & 1.143592 \\
\hline \multirow[t]{2}{*}{ Gender } & 1 & (omitted) & & & & \\
\hline & 1.036639 & 0.3481785 & 0.11 & 0.915 & 0.5367013 & 2.002271 \\
\hline \multirow{2}{*}{ Game Theory } & 1 & (omitted) & & & & \\
\hline & 1.230763 & 0.4302212 & 0.59 & 0.553 & 0.6203426 & 2.441842 \\
\hline Constant & 2201 & & & & & \\
\hline & Iטנק & 0.14 & & & 0.13 & \\
\hline
\end{tabular}

Std.Err. = Standard Error; Conf. $=$ Confidence.

\subsection{Questionnaire Data}

All the pairwise choices of a several statements about possible motives or beliefs were given to the participants to understand underlying reasons of the behavior during the experiment.

According to the Analytical Hierarchy Process [24], monopoly players strongly preferred an expected payoff maximization among the possible motives, and the belief that each decision of the 
monopoly players affects the behavior of all following entrants was assigned a higher weight than any other belief. The final result of the Analytical Hierarchy Process is that entrants intensely preferred a higher weight to the belief that entrants' choices were affected by the monopoly players' behavior on previous trials.

In other words, the post-experiment questionnaire shows that a significant majority of the monopoly players tried to earn more money, instead of that just sharing with the entrants an equal payoff. Also, a significant majority among the entrants reported that they took the decision-history of the monopoly players into consideration when making their choices. Thus, the questionnaire data shows that there is a (partial) support that both type participants believe their behavior is explained better by the rationale of the Deterrence Hypothesis than by the Equality Hypothesis.

\section{Discussion}

The new modelling of the Chain Store Story proposed by [4] was tested experimentally and the data collected in my experiment were analyzed to determine which of the two theories better account for the outcome: the Equality Hypothesis or the Deterrence Hypothesis. The other purpose is to experimentally study the dynamics of play, which aspects of the game affect behavior.

The experimental data cannot be explained fully by the rationale of the Equality Hypothesis nor by the rationale of the Deterrence Hypothesis. Each theory is favored by some evidence. Although the monopoly players played 'Cooperative' more frequently and the entrants chose 'In' more frequently, there are some behavioral patterns that share the same intuition with the Deterrence Hypothesis when I analyze the similarities in the decisions of the participants.

The outcome payoff 40 of the 'Cooperative-In' sequential equilibrium constitutes a reference point. Thus, it might have evaluated as an ideal point by the entrants and as the minimum payoff point by the monopoly players. I can support this conjecture with the observations: we see in the data the tendency of the entrants to 'In' play and the endeavor of the monopoly players to 'Aggressive' play. Moreover, we can separate the monopoly players into two groups: the ones who believed in the Equality Hypothesis and the ones who does not believe in this hypothesis. I conjecture that the ones who did not believe in the Equality Hypothesis interpreted each payoff over the 40 payoff as a gain, and therefore, they played less 'Aggressive' after reaching the 40 payoff since the target was already achieved.

The conducted logistic regressions suggest that both the entrants and the monopoly players considered the history of the session when making their choice. The entrants were affected by the past decisions of the monopoly players; since there was no available information for the monopoly players about the entrants regarding their past decisions, the monopoly players could only consider the outcomes of the previous rounds. In addition, LRI was not a significant predictor of 'Aggressive' decisions. This suggests that the monopoly players do not build their decisions just on a single reaction of the previous round; i.e., the monopoly players are farsighted. When considered together, these constitute the evidence that successive rounds were not perceived as independent-which can be interpreted as a contrast to the Equality Hypothesis and as support for the Deterrence Hypothesis. As the rounds progressed, the information on hand expanded and the participants played in relation to the information they obtained. Furthermore, the monopoly players who chose 'Aggressive' in response to the reactions to their past 'Aggressive' decisions declared that they played in a manner compatible with the essence of the Deterrence Hypothesis. Concisely, some monopoly players seem close to the path of the Deterrence Hypothesis, rather than to the path of the Equality Hypothesis. However, I cannot confirm this anticipation with the statistical evidence.

It seems to be easier for monopoly players than for the entrants to accept the idea of entry deterrence in both the CSG and Trockel's game. This is the case because monopoly players know that they will participate in a 20-stage game, in contrast to the entrants who focus only on a single-stage game. There is a statistically significant increase in the number of 'Aggressive' plays from T1 to T2, while the difference between the outcome payoffs in the two treatments does not affect the entrants. Yet, the results of the logistic regression analyses on the entrants' data indicate that the number of 'Non-Cooperative' 
plays affected the entrants. One can explain this by arguing that entrants were aware of the possible occurrence of effective deterrence at some stages even if they only made four choices.

Based on the discussions above, the equivalence in information in the original CSG and Trockel's game does not necessarily imply the same behavioral patterns or, in other words, it may not preserve strategic behavior. Although I cannot say that the data are compatible with the Deterrence Hypothesis, I see some evidence on the closeness of the logic/behavior of the agents towards the Deterrence Hypothesis. As [16] conjectured, Trockel's game presents an environment that allows for entry deterrence, as distinct from the CSG.

I would like to present a very important literature source stressing the importance of the contribution of my study. [25] had requested answers to the following questions: Whether there exist different extensive form games giving rise to the same strategic form game that are played differently and, if they are observed, whether these differences can be accounted for by principles reflecting recognizable differences between the extensive form games. Unknowingly, I asked a similar question: Does informational equivalence preserve strategic behavior? This study compared two different extensive form games giving rise to the same strategic form and the results—of this study and of [8] — establish that they are played differently. Moreover, my results provide insights concerning the reason for recognizable differences in the observed strategic behavior of players in these two extensive form games, namely having or not having structures built in the game model that allow for expressing and updating of beliefs.

Funding: Financial support was granted by Scientific and Technological Research Council of Turkey (TUBITAK, 215K424) and Istanbul Bilgi University(BAP). This work was partially supported by the German Research Foundation (DFG) within the Collaborative Research Center “On-The-Fly Computing" (SFB 901).

Acknowledgments: My thanks to Walter Trockel for calling my attention to this project. I wish to express my gratitude to Amnon Rapoport for all his critical comments and valuable hints, and to James Sundali. I wish to thank Ali Nesin and Nesin Mathematics Village, Deren Çağlayan, BELIS and BAEL for their support.

Conflicts of Interest: The author declares no conflict of interest.

\section{Appendix A}

The instructions and the questionnaires are translated from Turkish.

\section{Appendix A.1. Participant Instructions}

Thank you very much for your participation.

This is a decision-making experiment and your decisions will be used in a scientific project. During the experiment, in each step you will make a decision. There is no "correct" or "incorrect" answer. The only answer is "your" answer. The decisions you made, your answers and your earnings will not be matched with your name.

Your experiment earnings depend on the decisions you made, and this experiment booklet explains in detail how your earnings will be determined. It is, therefore, important to read and follow the instructions.

Until the experiment is finished, it is forbidden to communicate with the other participants in any possible way. If you have a question or a problem, please raise your hand and wait for the experimenter. Please avoid distracting the others and do not ask your questions aloud. Please turn your mobile phone's volume and vibration off.

\section{Appendix A.1.1. Types of Participants}

There are two types of participants: Type A and Type B. These types will be assigned at the beginning of the experiment and will not change during the experiment.

Four of 24 participants in this room will be type A, the remaining 20 participants will be type $\mathrm{B}$.

In addition, each participant will be randomly assigned a positive number with respect to his/her type and this order number will not be changed during the experiment. The purpose of this number is 
to save and follow your decisions. Thus, the participants in the room are numbered as A-1, A-2, A-3, A-4 and B-1, B-2, B-3, .., B-20.

\section{Appendix A.1.2. In-experiment Matchings}

The experiment contains 20 rounds. The 4 type A participants will be active in all 20 rounds. The 20 type B participants will be active in only 4 rounds. When the experiment starts, it will be determined randomly in which rounds which type B participants will be active and which type B participants will wait. Whenever they are active, they will be matched with which of type A participants. Then, all type B participants will be informed about this via their screen. The periods and how the experiment will proceed are explained in detail in the next sections.

In each round, all type A participants and the 4 type B participants chosen by the computer will be active. Thus, 4 encounters will take place in every round. The remaining 16 type B participants will wait until the next round, in which they will be active. Each of the 16 type B participants can see in which rounds she will be active and which of type A participants she will face when active.

Each type A faces a different type B participant in each round, so they face all 20 type B participants one by one. Also, each type B participant faces all type A participants: i.e., whenever she is active, the "opponent" type A participant is a different participant.

For type A participants, the experiment contains only 20 rounds in which they face 20 type B participants and is independent from the matches of other type A participants. For this reason, they are not informed about the matches of the other type A participants.

\section{Appendix A.1.3. Periods}

In each round, each of the activated participants will be given 1 point as a beginning point. Thus, every type A participant will be given 20 points in total and every type B participant will be given 4 points in total. You can change your points by the decisions you will make during the experiment.

The experiment starts with the 1st round. Each of the activated participants' points are activated. Type A participants start first. They are asked to decide between ' $Z$ ' and ' $T$ ' and their decisions will not be announced to any of the participants (including actives and non-actives) — they will be kept secret. After all type A participants decide, the active type B participants decide. They are asked to decide between ' $X$ ' and ' $Y$ ' without knowing the decision of the related type A participant. The points are given in Table A1.

Table A1. Payoff Table.

\begin{tabular}{|c|c|c|}
\hline & A's Point(s) & B's Point(s) \\
\hline $\mathrm{A}^{\prime}$ 's Decision is ' $\mathrm{Z}$ ' \& $\mathrm{B}$ 's Decision is ' $\mathrm{X}$ ' & 0 & 0 \\
\hline $\mathrm{A}^{\prime}$ 's Decision is ' $\mathrm{Z}$ ' \& B's Decision is ' $\mathrm{Y}$ ' & 5 & 1 \\
\hline $\mathrm{A}^{\prime}$ 's Decision is ' $\mathrm{T}$ ' \& $\mathrm{B}$ 's Decision is ' $\mathrm{X}$ ' & 2 & 2 \\
\hline $\mathrm{A}^{\prime}$ 's Decision is ' $\mathrm{T}$ ' \& B's Decision is ' $\mathrm{Y}$ ' & 5 & 1 \\
\hline
\end{tabular}

- If the decision of type A participant is $Z$ and the decision of type B participant is X, the points of the type A participant decrease by 1 point. Her earnings in this round are saved as 0 point.

- If the decision of type A participant is $\mathrm{Z}$ and the decision of type B participant is $\mathrm{Y}$, the points of the type A participant increase by 4 points. Her earnings in this round are saved as 5 points.

- If the decision of type A participant is $\mathrm{T}$ and the decision of type B participant is X, the points of the type A participant increase by 1 point. Her earnings in this round are saved as 2 points.

- If the decision of type A participant is $\mathrm{T}$ and the decision of type B participant is $\mathrm{Y}$, the points of the type A participant increase by 4 points. Her earnings in this round are saved as 5 points.

- If the decision of type A participant is $Z$ and the decision of type B participant is $X$, the points of the type $B$ participant decrease by 1 point. Her earnings in this round are saved as 0 point.

- If the decision of type A participant is $\mathrm{Z}$ and the decision of type B participant is $\mathrm{Y}$, the points of the type B participant remain constant. Her earnings in this round are saved as 1 point. 
- If the decision of type A participant is $\mathrm{T}$ and the decision of type B participant is $\mathrm{X}$, the points of the type $B$ participant increase by 1 point. Her earnings in this round are saved as 2 points.

- If the decision of type A participant is $\mathrm{T}$ and the decision of type B participant is $\mathrm{Y}$, the points of the type B participant remain constant. Her earnings in this round are saved as 1 point.

After the decisions are made and the earnings are saved, the earnings of each encounter are announced to the related active participants. Below, in Table A2, you can find an example of the announcement screens. (The values are changed.).

Table A2. Feedback Screens.

\begin{tabular}{llll}
\hline My Points & 0 & A's Points & 0 \\
\hline B's Points & 0 & My Points & 0 \\
\hline
\end{tabular}

After the earnings are announced, the 1st round ends. The 2 nd round starts with the new activated 4 type B participants. In the 2nd round, type A participants can view their own 1st round results and active type B participants can view the 1st round results of the related (faced) type A participant. Below, in Table A3, you can find the history table of the results. (The names of the decisions and the values are changed.).

Table A3. History Tables.

\begin{tabular}{cccc}
\hline Round & My Decision & My Opponent's Decision & My Points \\
\hline 1 & M & P & 9 \\
2 & $?$ & $?$ & $?$ \\
\hline Round & The Decision of B Who Was Active in That Round & The Points of B Who Was Active in That Round & A's Point \\
\hline 1 & P & 9 & 9 \\
2 & $?$ & $?$ & $?$ \\
\hline
\end{tabular}

The first table is an example of the history table that appears on the screen of each type A participant. With the help of this table, they can follow their own 1st round decision (1st column) as well as the earnings (2nd column), and the decision of the 1st round's active type B participant (3rd column). The second table is an example of the history table that appears on the screen of each active type B participant. Since the decisions of all type A participants are kept secret, each type B participant can only see the related type A participant's 1st round earnings (3rd column), but she can follow the decision (1st column) and the earnings (2nd column) of the 1st round's active type B participant.

After the 2nd round, which is identical to the 1st round in terms of stream, the 3rd round starts. The screens of the 3rd round's active participants are as presented in Figure A1 (The names of the decisions and the values are changed.).

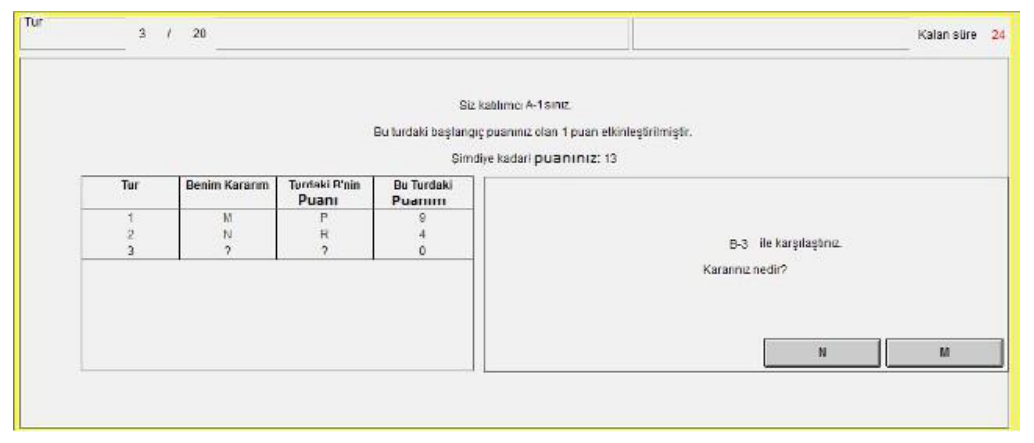

Figure A1. Type A's Screen Example.

From the writings above the tables, we can understand that it is A-1 who can view this screen. She earned 13 points in total from the first 2 rounds. From the box on the right side, we can see which 
of type B participant A-1 faced: In the 3rd round, A-1 and B-3 are matched and now A-1 must decide. If we examine the history table on the left side, in the 1st round A-1 chose ' $\mathrm{M}$ ' and the active type $B$ participant of that round chose ' $\mathrm{P}$ '. As the result of these decisions, A-1 added 9 points to her earnings. In the 2 nd round, $A-1$ chose ' $N$ ' and the active type B participant of that round chose ' $R$ '. As the result of these decisions, A- 1 added 4 points to her earnings. The total earnings of 13 is the sum of the earnings gained in the previous rounds. As is clear from the screen, the type A participant does not have any information related to this round's active type B participant, except her order number.

At the same time, B-3 views the screen given in Figure A2:

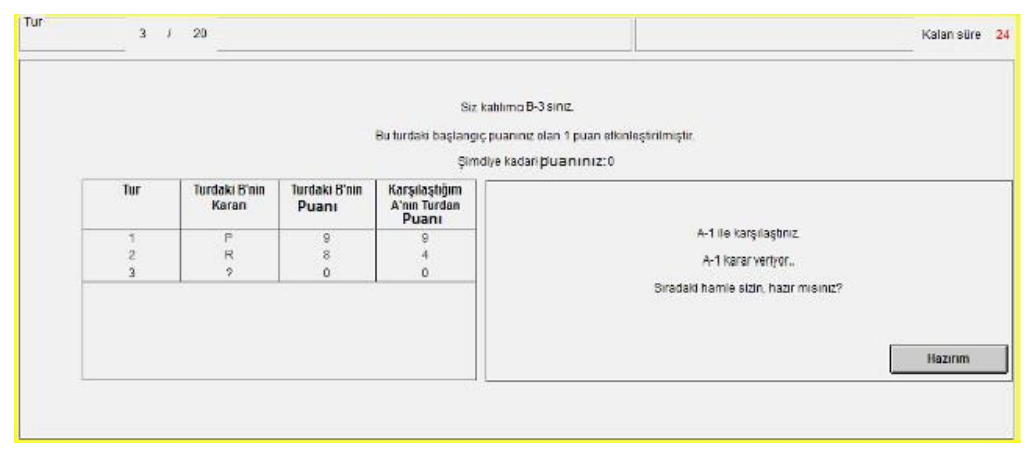

Figure A2. Type B’s Screen Example.

The total earnings of B-3 up to now are 0 . Either she has it as a result of her decision in one of the previous rounds or she has not decided yet. As we can understand from the box on the left side, the type B participant who faced A-1 in the 1st round chose ' $\mathrm{P}$ '. As a result, she added 9 points to her earnings and A-1 added 9 points to her earnings. The type B participant who faced A-1 in the 2 nd round chose ' $R$ '. As a result, she added 8 points to her earnings and A-1 added 4 points to her earnings. If we focus on the box on the right side, B-3 is waiting for the decision of A-1 and must push the button 'Ready'.

After the decisions of all type A participants, the active type B participants decide. While each of type B participants is deciding, the box on the right side of the screen of each type A participant changes to the new box, which states "B-3 decides.. After the decision, you will be informed in relation to your earnings.".

When each type B participant decides, the box on the right side of her screen changes to the new box "A-1 decided. What is your decision?" and shows the decision buttons ' $\mathrm{R}$ ' and ' $\mathrm{P}$ '.

After the decisions of all active participants and the earnings are saved as described above, the earnings are announced to the related active participants.

After the 3 rd round, the 4 th round starts. The history table is updated at the start of each newly beginning round. In summary, in each round you are in, you can obtain information related to all the previous rounds. If your type is A, you can access all the information. If your type is B, you can access all the information, except for the decisions of the related type A participant.

After the 20th round is finished as described above, the experiment will be finalized and a short questionnaire will be started.

Each type B participant will be active in only 4 of 20 rounds. When a type B participant is not active in a round, she can view the screen below: (the names of the decisions and the values are changed.).

The screen below (see Figure A3) belongs to B-15, who is not active in the 3rd round. From the box on the left side, we can see in which of the rounds B-15 is active. B-15 will be active in the 4 th round for the first time, then in the 7 th, 10 th and 16 th rounds. When she is active in the 4 th round, she will face A-3. The box on the top is the history table of the previous rounds of A-3. This table will be seen and will be updated in each round until B-15 faces A-3. Starting from the 5th round, the history table of all the previous rounds of A-1 will appear on the screen of B-15, since the next encounter will be with A-1. From the 8 th to the 10th round, the history table of all the previous rounds of A-2 will 
appear on her screen. From the 11th to the 20th round, the history table of all the previous rounds of A-4 will appear.

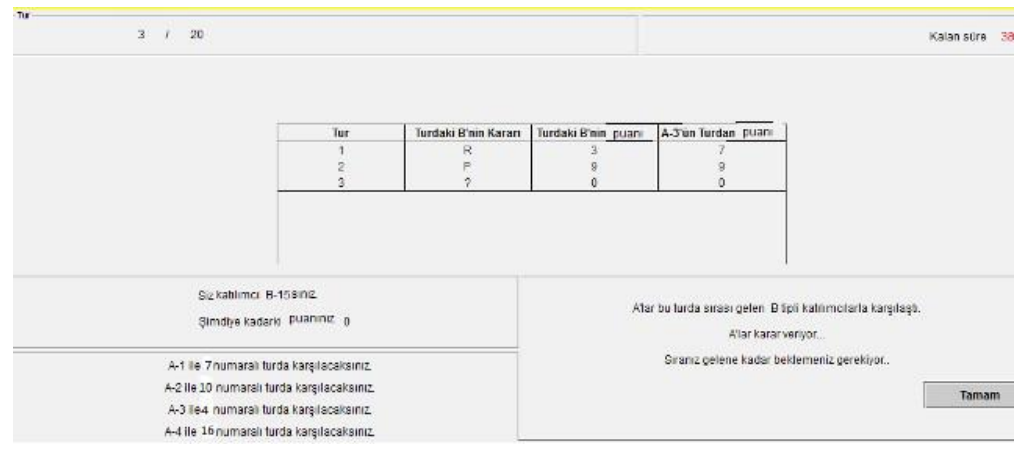

Figure A3. Waiting Type B's Screen Example.

In summary, each of the 16 waiting type B participants can view the history table of the type A participant that she will face next. In these tables, while the order number of the type A participant can be found, the order number of the type B participant who faced the same type A participant before cannot be seen.

After the active participants decide, their earnings and the decisions of the type B participants will be announced to all related type B participants who will face this related type A participant next.

Since type A participants will not be informed about the other type A participants' encounters, the decisions of active type B participants is available only to the type A participant that she faces, and these decisions cannot be reached by the other type A participants.

\section{Appendix A.1.4. In-experiment Earnings}

In each encounter, first the type A participant decides between ' $\mathrm{Z}$ ' and ' $\mathrm{T}$ ' (Remember, this decision will not be announced to anybody). Then the type B participant decides. Without knowing the decision of the type A participant, she will decide between ' $X$ ' and ' $Y$ '. The earnings in each round will be determined as we mentioned above.

The final earnings of a type A participant are the sum of the earnings she gained in each round. For example, if a type A participant gains $a_{1}, a_{2}, \ldots, a_{20}$ from the rounds respectively, her final earnings are $a_{1}+a_{2}+\ldots+a_{20}$ TL and this amount will be paid in cash in return for the receipts on your table.

The final earnings of a type B participant are 5 times the sum of the earnings she gained in each round. For example, if a type B participant gains $b_{1}, b_{2}, b_{3}, b_{4}$ from the rounds respectively, her final earnings are $5 *\left(b_{1}+b_{2}+b_{3}+b_{4}\right)$ TL and this amount will be paid in cash in return for the receipts on your table.

\section{Appendix A.2. Questionnaire}

Independently from the types of the participants, the participants are asked to give information related to their age, gender, faculty and whether they have information on Game Theory.

\section{Appendix A.2.1. Type A Questionnaire 1}

Please read carefully and answer the questions below considering how you decided during the experiment.

(A) I tried to earn as much as I can. I played by trying to maximize my earnings.

(B) I tried to be fair towards type B participants. For me, the total of the earnings of all participants was also important, I did not consider only myself.

(C) As a type A participant, the most important thing was my reputation. I tried to be a 'tough' player, not to make type B participants benefit.

(D) My decisions depend on other reasons. 
Please compare the given two options below regarding which of the options explains your behavior during the experiment. Please mark your choice.

If you cannot decide between two options, please mark INDIFFERENT.

o A ( ) B ( ) Indifferent ( )

o B ( ) C ( ) Indifferent ( )

o C ( ) A ( ) Indifferent ( )

o A ( ) D ( ) Indifferent ( )

o D ( ) C ( ) Indifferent ( )

o B ( ) D ( ) Indifferent ( )

Any comments?

Appendix A.2.2. Type B Questionnaire

Please read carefully and answer the questions below regarding how you decided during the experiment.

(A) Whomever I faced, my strategy was to always play ' $\mathrm{X}$ ' or always ' $\mathrm{Y}$ '.

(B) I made my choices between ' $X$ ' and ' $Y$ ' considering the number of the round in which I decided.

(C) My decisions depend on other reasons.

(D) I made my choices between ' $X$ ' and ' $Y$ ' considering the ideas and the beliefs about the type A participant I faced. I examined how she played in comparison to the other type B participants before me.

Please compare the given two options below regarding which of the options explains your behavior during the experiment. Please mark your choice.

If you cannot decide between two options, please mark INDIFFERENT.

o A ( ) B ( ) Indifferent ( )

o B ( ) C ( ) Indifferent ( )

o C ( ) A ( ) Indifferent ( )

o A ( ) D ( ) Indifferent ( )

o D ( ) C ( ) Indifferent ( )

o B ( ) D ( ) Indifferent ( )

Any comments?

Appendix A.2.3. Type A Questionnaire 2

Please read carefully and answer the questions below regarding how you decided during the experiment.

(A) In each round I decided independently from the other rounds. I did not think that my decision to a type B participant could affect the other type B participants' decisions.

(B) I thought that my decision to a type B participant could affect the following type B participant's decision and only this participant.

(C) I thought that my decision to a type B participant could affect all of the following type B participants' decisions.

(D) I thought that my decision to a type B participant could affect all the following type B participants' decisions, except a few of them from the last round.

Please compare the given two options below regarding which of the options explains your behavior during the experiment. Please mark your choice.

If you cannot decide between two options, please mark INDIFFERENT.

o A ( ) B ( ) Indifferent ( )

o B ( ) C ( ) Indifferent ( )

o C ( ) A ( ) Indifferent ( ) 
o A ( ) D ( ) Indifferent ( )

o D ( ) C ( ) Indifferent ( )

o B ( ) D ( ) Indifferent ( )

Any comments?

\section{References}

1. Selten, R. The chain store paradox. Theory Decis. 1978, 9, 127-159. [CrossRef]

2. Kreps, D.M.; Wilson, R. Reputation and imperfect information. J. Econ. Theory 1982, 27, 253-279. [CrossRef]

3. Milgrom, P.; Roberts, J. Predation, reputation, and entry deterrence. J. Econ. Theory 1982, 27, $280-312$. [CrossRef]

4. Trockel, W. The chain-store paradox revisited. Theory Decis. 1986, 21, 163-179. [CrossRef]

5. Dalkey, N. Equivalence of information patterns and essentially determinate games. In Contributions to the Theory of Games; Kuhn, H.W., Tucker, A.W., Eds.; Princeton University Press: Princeton, NJ, USA, 1953; Volume 2, pp. 217-244.

6. Thompson, F.A. Equivalence of games in extensive form. In Classics in Game Theory; Kuhn, H.W., Ed.; Princeton University Press: Princeton, NJ, USA, 1997; pp. 36-45.

7. Malinvaud, E. Note on von Neumann-Morgenstern's strong independence axiom. Econom. J. Econom. Soc. 1952, 20, 679. [CrossRef]

8. Sundali, J.A.; Rapoport, A. Induction vs. Deterrence in the Chain Store Game: How Many Potential Entrants are Needed to Deter Entry?. In Understanding Strategic Interaction; Albers W., Güth W., Hammerstein P., Moldovanu B., van Damme E., Eds.; Springer: Berlin/Heidelberg, Germany, 1997; pp. 403-417.

9. Posner, R.A. Economic Analysis of Law; Wolters Kluwer Law \& Business: New York, NY, USA, 2014.

10. Gates, S.; Humes, B.D. Games, Information, and Politics: Applying Game Theoretic Models to Political Science; University of Michigan Press: Ann Arbor, MI, USA, 1997.

11. Camerer, C.; Weigelt, K. Experimental tests of a sequential equilibrium reputation model. Econom. J. Econom. Soc. 1988, 56, 1-36. [CrossRef]

12. Jung, Y.J.; Kagel, J.H.; Levin, D. On the existence of predatory pricing: An experimental study of reputation and entry deterrence in the chain-store game. RAND J. Econ. 1994, 25, 72-93. [CrossRef]

13. Sundali, J.; Israeli, A.; Janicki, T. Reputation and deterrence: Experimental evidence from the Chain Store Game. J. Bus. Econ. Stud. 2000, 6, 1.

14. Benard, S. Reputation systems, aggression, and deterrence in social interaction. Soc. Sci. Res. 2013, 42, $230-245$. [CrossRef] [PubMed]

15. Neugebauer, T. Airness and reciprocity in the hawk-dove game. J. Econ. Behav. Organ. 2008, 66, $243-250$. [CrossRef]

16. Sundali, J. An Experimental Investigation of Market Entry Problems. Ph.D. Thesis, The University of Arizona, Tucson, AZ, USA, 1995.

17. Kahneman, D.; Tversky, A. Prospect theory: An analysis of decision under risk. Econom. J. Econom. Soc. 1979, 47, 263-291. [CrossRef]

18. Tversky, A.; Kahneman, D. The framing of decisions and the psychology of choice. Science 1981, 211, 453-458. [CrossRef] [PubMed]

19. Rapoport, A. Order of play in strategically equivalent games in extensive form. Int. J. Game Theory 1997, 26, 113-136. [CrossRef]

20. Güth, W.; Huck, S.; Rapoport, A. The limitations of the positional order effect: Can it support silent threats and non-equilibrium behavior? J. Econ. Behav. Organ. 1998, 34, 313-325. [CrossRef]

21. Fischbacher, U. z-Tree: Zurich toolbox for ready-made economic experiments. Exp. Econ. 2007, 10, 171-178. [CrossRef]

22. Greiner, B. The Online Recruitment System ORSEE 2.0. A Guide for the Organization of Experiments in Economics Work. Pap. Ser. Econ. 2004, 10, 63-104. 
23. Selten, R.; Stoecker, R. End behavior in sequences of finite Prisoner's Dilemma supergames: A learning theory approach. J. Econ. Behav. Organ. 1986, 7, 47-70. [CrossRef]

24. Saaty, T.L. The Analytic Hierarchy Process; McGraw Hill: New York, NY, USA, 1980.

25. Kreps, D.M. Game Theory and Economic Modelling; Oxford University Press: Oxford, UK, 1990.

(C) 2020 by the authors. Licensee MDPI, Basel, Switzerland. This article is an open access article distributed under the terms and conditions of the Creative Commons Attribution (CC BY) license (http:// creativecommons.org/licenses/by/4.0/). 